Special Issue of the 6th International Congress \& Exhibition (APMAS2016), Maslak, Istanbul, Turkey, June 1-3, 2016

\title{
Analysis of Surface Modification of GFRP and Influence on the Drilled Part Delamination
}

\author{
I. Cavusoglu ${ }^{a, *}$, M.N. Durakbasa ${ }^{b}$ And M. CakiR ${ }^{c}$ \\ ${ }^{a}$ Marmara University, Vocational School of Technical Sciences, Mechanical and Metal Technology Deptartment, \\ 34722, Kadıköy, İstanbul, Turkey \\ ${ }^{b}$ Vienna University of Technology, Interchangeable Manufacturing and Industrial Metrology of Institute \\ for Production Engineering and Laver Technology, 1060 Getreidemarkt 9, BA-09, Wien, Austria \\ ${ }^{c}$ Marmara University, Faculty of Technology, Metallurgical and Materials Engineering Department, \\ 34722, Kadıköy, İstanbul, Turkey
}

\begin{abstract}
Glass fibre reinforced plastics are especially used in aviation industry, marine applications, automobile industry and wind power plants. The shape of the products to be manufactured from glass fibre reinforced plastics materials can be easily produced by using different primary methods [J.-M. Bertholet, Composite Materials, Springer, New York 2012, p. 54]. Assembly is necessary to create the final products which have been fabricated from glass fibre reinforced plastics. Components manufactured from glass fibre reinforced plastics are drilled with CNC, during assembling process. Several kinds of defects occur around the hole after drilling the materials. Presence of defects influences the quality of holes and of the products. The aim of this study is to make comparison between modified and unmodified composite materials, both of which are formed of $30 \%$ of glass fibres and $70 \%$ of epoxy resin, in terms of delamination factor. Influence of surface modification is evaluated to identify optimum drilling parameters by using Taguchi orthogonal L18 matrix. Surface condition, drill diameter, spindle speed and feed rate are changed as process parameters in the experiments. According to the study, feed rate and spindle speed are the most influential parameters and the drill tool surface condition does not show any general change.
\end{abstract}

DOI: 10.12693/APhysPolA.131.423

PACS/topics: 72.80.Tm

\section{Introduction}

The most attractive properties of composite materials are high mechanical strength and small weight, which provide energy saving in many industries. Glass fibre reinforced plastic (GFRP) products mostly need to be drilled. Deformations occurring after drilling of GFRP are evaluated directly using such parameters as damage width, delaminated area or delamination factor, and indirectly through thrust force, torque or power [1]. Some researchers, such as C.C. Tsao and E. Kilickap [2-5], have made direct deformation evaluation on the carbon fiber reinforced plastics (CFRP) and GFRP. Another researcher has conducted drilling experiments on E-glass reinforced plastic composites to evaluate delamination factor by using response surface methodology (RSM) [2]. C.C. Tsao [3], while studying on delamination of CFRP composites by using RSM has based on Taguchi with L18 matrix method. E. Kilickap [4] has worked on GFRP composite to evaluate the influence of cutting parameters on the delamination factor by using Taguchi and ANOVA. J. Campos Rubio et al. [5] have investigated the delamination factor by comparing the conventional $\left(F_{\mathrm{d}}\right)$ and adjusted $\left(F_{\mathrm{da}}\right)$ delamination on GFRP. On the other hand, there are some other investigators, including

*corresponding author; e-mail: ilknur@marmara.edu.tr
K. Palanikumar [6-9] who made research on deformation by using indirect performance characteristics. V.K. Vankanti et al. [6] have investigated how cutting speed, feed point angle and chisel edge as process parameters affect the thrust force, torque and circularity of the hole in drilling of GFRP composites. K. Palanikumar [7] has also worked on GFRP composite materials by using the Taguchi method with Grey relational analysis to evaluate the performance characteristics, such as thrust force, surface roughness and delamination factor. Furthermore, I.S. Shyha et al. [8] have evaluated thrust force, torque, tool life and delamination of exit and entry on CFRP by using Taguchi L12 matrix with ANOVA. In addition H. Hocheng et al. [9] have studied drilling of GFRP to examine correlation between the drilling-induced delamination and thrust force.

\section{Materials and equipment}

Epoxy resins (EPIKOTE 828) and hardener (F-205) are supplied by Huntsman. Accelerator benzyl dimethyl amine (BDMA) is supplied by Sigma-Aldrich. E-glass fibre fabric is obtained from Cam Elyaf ${ }^{\circledR}$, glass fiber CD 125-500. (3-Aminopropyl) triethoxysilane (APTES) and hydrochloric acid $(\mathrm{HCl})$, which were used for surface modification, were obtained from Sigma-Aldrich.

In this study, both modified and unmodified GFRP composites have included $30 \%$ of glass fiber. Matrix material contains epoxy resin, hardener and BDMA 
TABLE I

Mechanical properties and chemical composition of GFRPs.

\begin{tabular}{c|c|c|c|c|c|c|c}
\hline \multirow{2}{*}{ Metarials } & \multicolumn{4}{|c|}{ Mechanical properties } & $\begin{array}{c}\text { Reinforcing } \\
\text { materials }\end{array}$ & \multicolumn{3}{|c}{ Matrix materials } \\
\cline { 2 - 7 } & $\begin{array}{c}E \text { module } \\
{\left[\mathrm{N} / \mathrm{mm}^{2}\right]}\end{array}$ & $\begin{array}{c}\text { Tensile } \\
\text { strength } \\
{\left[\mathrm{N} / \mathrm{mm}^{2}\right]}\end{array}$ & $\begin{array}{c}\text { Izod impact } \\
\text { test } \\
{\left[\mathrm{kJ} / \mathrm{m}^{2}\right]}\end{array}$ & $\begin{array}{c}\text { Glass fibre } \\
\text { (E-glass) } \\
\text { ratio [\%] }\end{array}$ & $\begin{array}{c}\text { Epoxy resin } \\
\text { ratio (Epikote 828) } \\
{[\%]}\end{array}$ & $\begin{array}{c}\text { Hardener } \\
\text { ratio (F205) } \\
{[\%]}\end{array}$ & $\begin{array}{c}\text { Accelerator } \\
(\mathrm{BDMA}) \\
{[\%]}\end{array}$ \\
\hline $\begin{array}{c}\text { Fiber surface } \\
\text { unmodified }\end{array}$ & 3254 & 201 & 24.7 & 30 & 43.86 & 25.44 & 0.70 \\
$\begin{array}{c}\text { Fiber surface } \\
\text { modified }\end{array}$ & 3811 & 172 & 19.3 & 30 & 43.86 & 25.44 & 0.70
\end{tabular}

TABLE II

L18 experiment matrix level for one factor 2 level and three factors 3 level for Taguchi experiment plan.

\begin{tabular}{|c|c|c|c|c|c|c|c|c|}
\hline \multirow[b]{3}{*}{ Exp. } & \multicolumn{4}{|c|}{ Factors and levels } & \multicolumn{4}{|c|}{ Experiment results } \\
\hline & \multirow{2}{*}{$\begin{array}{c}\text { A } \\
\text { Surface } \\
\text { condition }\end{array}$} & \multirow{2}{*}{$\begin{array}{c}\text { B } \\
\text { Drill } \\
\text { diameter } \\
{[\mathrm{mm}]}\end{array}$} & \multirow{2}{*}{$\begin{array}{c}\text { C } \\
\text { Spindle } \\
\text { speed } \\
\text { [rpm] }\end{array}$} & \multirow{2}{*}{$\begin{array}{c}\mathrm{D} \\
\text { Feed } \\
\text { rate } \\
{[\mathrm{mm} / \mathrm{min}]}\end{array}$} & \multicolumn{2}{|c|}{$30 \%$ Unmodified } & \multicolumn{2}{|c|}{$30 \%$ Modified } \\
\hline & & & & & $\begin{array}{l}\text { Mean } \\
\text { of } F_{\mathrm{d}}\end{array}$ & $\begin{array}{c}\mathrm{S} / \mathrm{N} \text { rate } \\
{[\mathrm{dB}]}\end{array}$ & $\begin{array}{l}\text { Mean } \\
\text { of } F_{\mathrm{d}}\end{array}$ & $\begin{array}{c}\mathrm{S} / \mathrm{N} \text { rate } \\
{[\mathrm{dB}]}\end{array}$ \\
\hline 1 & TiN & 4 & 2000 & 240 & 1.0853 & -0.7136 & 1.0555 & -0.4696 \\
\hline 2 & $\mathrm{TiN}$ & 4 & 2800 & 480 & 1.2540 & -2.0202 & 1.0427 & -0.3636 \\
\hline 3 & $\mathrm{TiN}$ & 4 & 3600 & 720 & 1.1172 & -0.9637 & 1.0830 & -0.6928 \\
\hline 4 & $\mathrm{TiN}$ & 5 & 2000 & 480 & 1.3497 & -2.6312 & 1.0949 & -0.7991 \\
\hline 5 & $\mathrm{TiN}$ & 5 & 2800 & 720 & 1.3148 & -2.3907 & 1.0803 & -0.6727 \\
\hline 6 & $\mathrm{TiN}$ & 5 & 3600 & 240 & 1.0773 & -0.6481 & 1.0352 & -0.3011 \\
\hline 7 & TiN & 6 & 2000 & 240 & 1.2008 & -1.6631 & 1.0272 & -0.02336 \\
\hline 8 & $\mathrm{TiN}$ & 6 & 2800 & 480 & 1.1803 & -1.4669 & 1.0454 & -0.3864 \\
\hline 9 & TiN & 6 & 3600 & 720 & 1.1268 & -1.0384 & 1.0559 & -0.4732 \\
\hline 10 & Uncoated & 4 & 2000 & 720 & 1.4737 & -3.3722 & 1.2346 & -1.8363 \\
\hline 11 & Uncoated & 4 & 2800 & 240 & 1.0757 & -0.6353 & 1.0326 & -0.2791 \\
\hline 12 & Uncoated & 4 & 3600 & 480 & 1.1020 & -0.8472 & 1.0319 & -0.2730 \\
\hline 13 & Uncoated & 5 & 2000 & 720 & 1.3717 & -2.7739 & 1.1433 & -1.1651 \\
\hline 14 & Uncoated & 5 & 2800 & 240 & 1.0865 & -0.7473 & 1.0303 & -0.2599 \\
\hline 15 & Uncoated & 5 & 3600 & 480 & 1.0853 & -0.7126 & 1.0236 & -0.2031 \\
\hline 16 & Uncoated & 6 & 2000 & 480 & 1.1570 & -1.2759 & 1.0820 & -0.6878 \\
\hline 17 & Uncoated & 6 & 2800 & 720 & 1.1335 & -1.0914 & 1.0869 & -0.7279 \\
\hline 18 & Uncoated & 6 & 3600 & 240 & 1.0926 & -0.7745 & 1.0243 & -0.2091 \\
\hline
\end{tabular}

(as an accelerator). This cold cure resin system is used in laboratory in vacuum assisted resin transfer molding with the size of $4 \times 250 \times 250 \mathrm{~mm}^{3}$, at room temperature. The mechanical properties and chemical composition of both GFRPs are shown in Table I.

Hydrolyzed fibers are washed with ethanol and then the surfaces of fibers are modified with amine function groups of pre-hydrolyzed APTES via sol-gel method. Then, the fibers are washed with ethanol three times and dried in vacuum drying-oven for a night. The composites are manufactured with a ratio of $30 \mathrm{wt} . \%$ of amine function glass fiber.

Surface modification affects positively the delamination [10]. The tensile strength of the composite is decreased after surface modification by APTES, however that decrease can be neglected due to the sound contribution of the delamination. In Table I the mechanical properties of both materials are shown.

Conventional twist drill bits with 4, 5 and $6 \mathrm{~mm}$ diameter made of high speed steel (HSS-E), gold collection and bits coated with TiN, gold collection, were used for drilling the materials. Chemical components of tools used are $0.9 \% \mathrm{C}, 4.1 \% \mathrm{Cr}, 4.9 \% \mathrm{Mo}, 1.8 \% \mathrm{~V}, 6.3 \% \mathrm{~W}, 4.8 \% \mathrm{Co}$ for both HSS-E and HSS-E+Tin. Point angles of these tools were $135^{\circ}$. All tests were carried out without coolant liquid. Both GFRPs were drilled in John Ford VMC550A CNC machining center. This machine can operate at $60-6000 \mathrm{rpm}$ spindle speed and at $0-4000 \mathrm{~mm} / \mathrm{min}$ cutting feed rate.

Taguchi has improved a series of statistical methods that are used as a performance criterion, called signal to noise ratio, with the aim of reducing variation in the 
design of experiment. Taguchi classified problems in the usage into three categories according to the type of target, and then identified different signal/noise ratios for each them. The categories are "the-lower-better", "thehigher-better" and "the-nominal-better. The aim is to reach the level with the greatest $\mathrm{S} / \mathrm{N}$ ratio which gives the best performance in each kind of the three problems [11-13].

In the present work, the effect of surface modification on the delamination factor in glass fibre composite material (reinforced with $30 \mathrm{wt} . \%$ ) is investigated. The surface modification is studied to see whether it is possible to increase the quality of the drilled holes. Both modified and unmodified work pieces are drilled according to L18 matrix, which was designed using Taguchi's experiment design for four different factors, which are A (a two level factor) and the others B, C, D are three level. Each experiment was repeated three times. Table II shows the prepared planning for L18 matrix and also the S/N ratio values. In this study, deformation of the GFRP, which occurred after drilling, was interpreted by using delamination as the evaluation method. The measurements are made using Zeiss SteReo Discovery V20 microscope which is equipped with PlanApo S 1.0x $60 \mathrm{~mm}$ objective and Zeiss AxioCam Icc 5 camera. Maximum magnification of the microscope used for characteriza- tion was $150 \times$ and its maximum resolution was $2.33 \mu \mathrm{m}$. In the study, all holes and the damage around the holes were measured with $13 \times$ magnification.

The delamination factor was determined as

$$
F_{\mathrm{d}}=\frac{D_{\max }}{D_{0}},
$$

where $D_{\max }$ is the maximum diameter of the damaged zone and $D_{0}$ is the diameter of the hole [14].

In this case study, the delamination factor should have the lowest value, therefore "the-smaller-the-better" method is utilized for computation of $\mathrm{S} / \mathrm{N}$ ratio in the analysis of the experiments. The $\mathrm{S} / \mathrm{N}$ ratio of "the-smallerthe-better" characteristic is presented as follows,

$$
\eta=-10 \log _{10}\left[\frac{1}{n} \sum_{i=1}^{n} y_{i}^{2}\right],
$$

where $y$ is the observed parameter and $n$ is the number of observations in the formula. Minitab 17 was used to calculate the $\mathrm{S} / \mathrm{N}$ ratio and for Taguchi analysis.

\section{Results and discussion}

In this case, delamination should have a small value, that is why "the-smaller-the-better" is chosen for Taguchi design of experiment.

TABLE III

\begin{tabular}{|c|c|c|c|c|c|c|c|c|c|c|c|c|}
\hline & \multirow[t]{2}{*}{ Factor } & \multirow[t]{2}{*}{$\mathrm{df}$} & \multicolumn{3}{|c|}{ Avearage $\mathrm{S} / \mathrm{N}$ ratio $[\mathrm{dB}]$} & \multirow[t]{2}{*}{ Seq SS } & \multirow[t]{2}{*}{ Adj MS } & \multirow[t]{2}{*}{ Adj MS } & \multirow[t]{2}{*}{$\mathrm{F}$} & \multirow[t]{2}{*}{$\mathrm{P}$} & \multirow[t]{2}{*}{ Delta } & \multirow[t]{2}{*}{ Rank } \\
\hline & & & 1. Level & 2. Level & 3. Level & & & & & & & \\
\hline \multirow{6}{*}{ 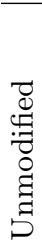 } & A & 1 & -1.5040 & -1.3590 & - & 0.0947 & 0.0947 & 0.0947 & 0.26 & 0.618 & 0.1451 & 4 \\
\hline & B & 2 & -1.4254 & -1.6507 & -1.2184 & 0.5609 & 0.5609 & 0.2805 & 0.78 & 0.483 & 0.4323 & 3 \\
\hline & $\mathrm{C}$ & 2 & -2.0717 & -1.3920 & -0.8308 & 4.6338 & 4.6338 & 2.3169 & 6.48 & $0.016^{*}$ & 1.2409 & 1 \\
\hline & $\mathrm{D}$ & 2 & -0.8637 & -1.4924 & -1.9385 & 3.4986 & 3.4986 & 1.7493 & 4.89 & $0.033^{*}$ & 1.0748 & 2 \\
\hline & Error & 46 & & & & 3.5758 & 3.5758 & 0.0777 & & & & \\
\hline & Total & 53 & & & & 12.3638 & & & & & & \\
\hline \multirow{6}{*}{ 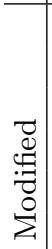 } & A & 1 & -0.4881 & -0.6269 & - & 0.0867 & 0.0867 & 0.0867 & 1.77 & 0.213 & 0.1388 & 4 \\
\hline & $\mathrm{B}$ & 2 & -0.6525 & -0.5669 & -0.4531 & 0.1201 & 0.1201 & 0.0601 & 1.22 & 0.334 & 0.1994 & 3 \\
\hline & $\mathrm{C}$ & 2 & -0.8653 & -0.4483 & -0.3588 & 0.8769 & 0.8769 & 0.4384 & 8.94 & $0.006^{*}$ & 0.5065 & 2 \\
\hline & $\mathrm{D}$ & 2 & -0.2921 & -0.4522 & -0.9280 & 1.3129 & 1.3129 & 0.6564 & 13.39 & $0.001^{*}$ & 0.6359 & 1 \\
\hline & Error & 46 & & & & 0.4902 & 0.4902 & 0.0107 & & & & \\
\hline & Total & 53 & & & & 2.8867 & & & & & & \\
\hline
\end{tabular}

Response table for signal to noise ratios "smaller is better" for $30 \%$ unmodified and modified GFRP.

Taguchi analysis of response for signal to noise $(\mathrm{S} / \mathrm{N})$ ratio is given in Table III for unmodified GFRP. From the analysis the spindle speed and feed rate are significant at the $5 \%$ level $(p<0.05)$. Spindle speed and feed rate are the most important factors among the four chosen factors for 30\% unmodified GFRP. The most significant factor is spindle speed as its slope gradient is very high in Fig. 1a. It could be seen that choosing $\mathrm{A}_{2} \mathrm{~B}_{3} \mathrm{C}_{3} \mathrm{D}_{1}$ results in the optimum factor level combination for getting the lowest delamination during the drilling process. On the other side, feed rate is the most important factor for the the surface-modified sample. Feed rate and spindle speed are also more significant than the surface condition and drill diameter for $30 \%$ modified GFRP in Fig. 1b. It could be seen that choosing $A_{1} B_{3} C_{3} D_{1}$ results in the optimum factor level combination for getting lowest delamination during the drilling process. Taguchi analysis of response table for signal to noises $(\mathrm{S} / \mathrm{N})$ ratio is given in Table III 


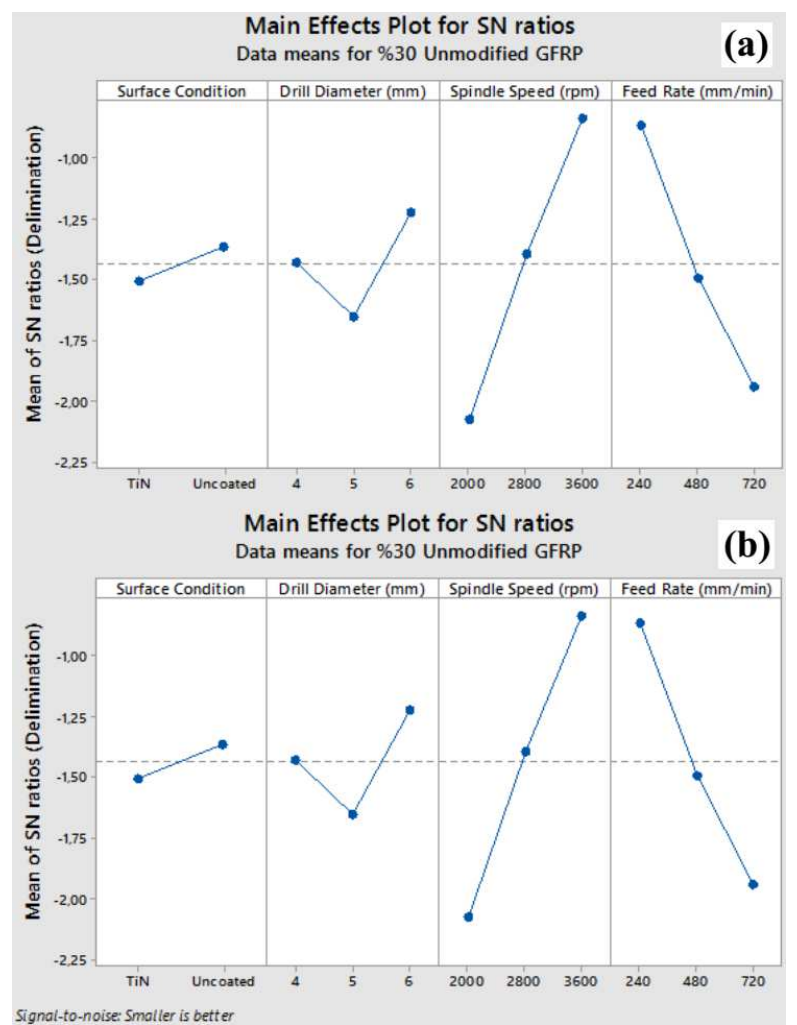

Fig. 1. (a) Main effects plot for 30\% unmodified GFRP, (b) main effects plot for 30\% modified GFRP.

for $30 \%$ modified GFRP. Feed rate and spindle speed are also significant at the $5 \%$ level $(p<0.05)$ in the results of analysis of variance for $\mathrm{S} / \mathrm{N}$ ratios for $30 \%$ modified GFRP. Drilling tool surface condition, presence or absence of tin coating, are not influential factors for both GFRP parts.

When looking at the delamination value for both unmodified and modified parts in Table II, there is a noticeable variety between the values of two materials. Surface modification of the part significantly decreased delamination factor in Fig. 2. If the composite material is modified, both the diminishing of the delamination factor and diminishing of shape deformation are shown in the study. Deformation, fiber break-off, and also large scale deformation occur around the holes of the modified piece.

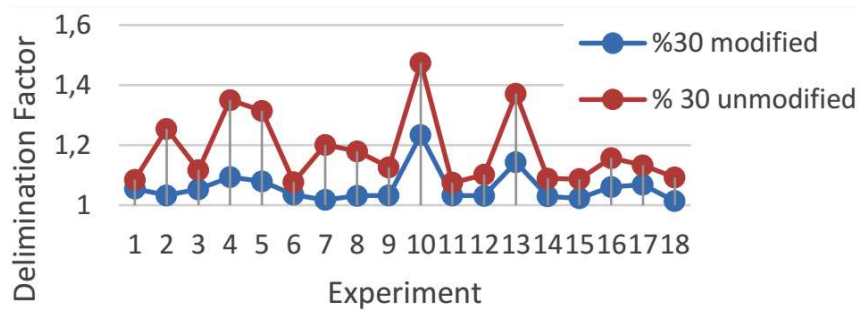

Fig. 2. Mean delamination factor distribution of modified and unmodified GFRP.
Thermoset, although it is not a recycling material, is commonly used for manufacturing of GFRP parts. Therefore, increasing the duration of composite product utilization not only contributes to increasing quality but also reduces the negative impacts on the environment.

\section{Conclusions}

Delamination on the GFRP is evaluated using experimental design factors, such as surface condition, drill diameter, spindle speed and feed rate. Looking through literature studies on the subject, it can be seen that the most influential factors on delamination factor of GFRP materials of all machining parameters are the spindle speed and feed rate.

The following conclusions are drawn from this study:

1. Selected machining tool surface condition, coated or uncoated, is not an efficient factor. Using TiN coated tools on modified and uncoated tools on unmodified parts give optimal results in the examination.

2. The increase in drill diameter decreases the delamination factor in drilling on both composite materials.

3. The delamination factor decreases slightly with the increase of spindle speed for both materials.

4. The delamination factor increases with the increase of feed rate for each of the materials.

5. Less deformation and less defects occur on the modified composite. Not only larger delamination, but also a more irregular shape of delamination is produced on the $30 \%$ unmodified GFRP.

\section{Acknowledgments}

This research is partially supported within the scope of TUBITAK 2219. All measurements were made in nanotechnology laboratory of the Department of Interchangeable Manufacturing and Industrial Metrology of Institute for Production Engineering and Laser Technology at Vienna University of Technology.

\section{References}

[1] A.M. Abrao, P.E. Faria, J.C.C. Rubio, P. Reis, J.P. Davim, J. Mat. Proc. Tech. 186, 1 (2007).

[2] T.V. Rajamurugan, K. Shanmugam, K. Palanikumar, Mat. Des. 45, 80 (2013).

[3] C.C. Tsao, Inter. J. Adv. Manu. Tech. 62, 241 (2012).

[4] E. Kilickap, Exp. Sys. With Appl. 37, 6116 (2010).

[5] J.C. Rubio, A.M. Abrao, P.E. Faria, A.E. Correia, J.P. Davim, Int. J. Mach. T. Manu. 48, 715 (2008). 
[6] V.K. Vankanti, V. Ganta, J. Mat. Res. Tech. 3, 35 (2014).

[7] K. Palanikumar, Meas. 44, 2138 (2011).

[8] I.S. Shyha, D.K. Aspinwall, S.L. Soo, S. Bradley, Int. J. Mach. T. Manu. 49, 1008 (2009).

[9] H. Hocheng, C.C. Tsao, Int. J. Mach. T. Manu. 46, 1403 (2006).

[10] N.P. Cheremisinoff, Handbook of Ceramics and Composites, Vol: 1, Synthesis and Properties, CRC Press, p. 367.
[11] N.S. Mohan, A. Ramachandra, S.M. Kulkarni, Com. Struc. 71, 407 (2005)

[12] C.C. Tsao, Int. J. Adv. Man. Tech. 36, 11 (2008).

[13] V.K. Vankanti, V. Ganta, J. Mat. Res. Tech. 3, 35 (2014).

[14] S.R. Karnik, V.N. Gaitonde, J.C. Rudio, A.E. Correia, A.M. Abrao, J.P. Davim, Mat. Des. 29, 1768 (2008). 